\title{
Medicaid: An Overview
}

\author{
Gilbert Berdine $M D$
}

Medicaid was established by the Social Security Amendments of 1965. These amendments included Title XVIII and XIX of the Social Security Act. Title XVIII created Medicare and Title XIX created Medicaid. Medicaid was established as a health care entitlement to low income families meeting certain eligibility criteria. The eligible were the blind, the aged, and disabled people as well as pregnant women. During its initial fiscal year (1966), Medicaid delivered $\$ 0.9$ billion in assistance to 4.0 million enrollees for an average benefit of $\$ 225$. Medicaid has grown since then to deliver $\$ 427.4$ billion in assistance to 55.7 million enrollees for an average benefit of $\$ 7673 .{ }^{1}$

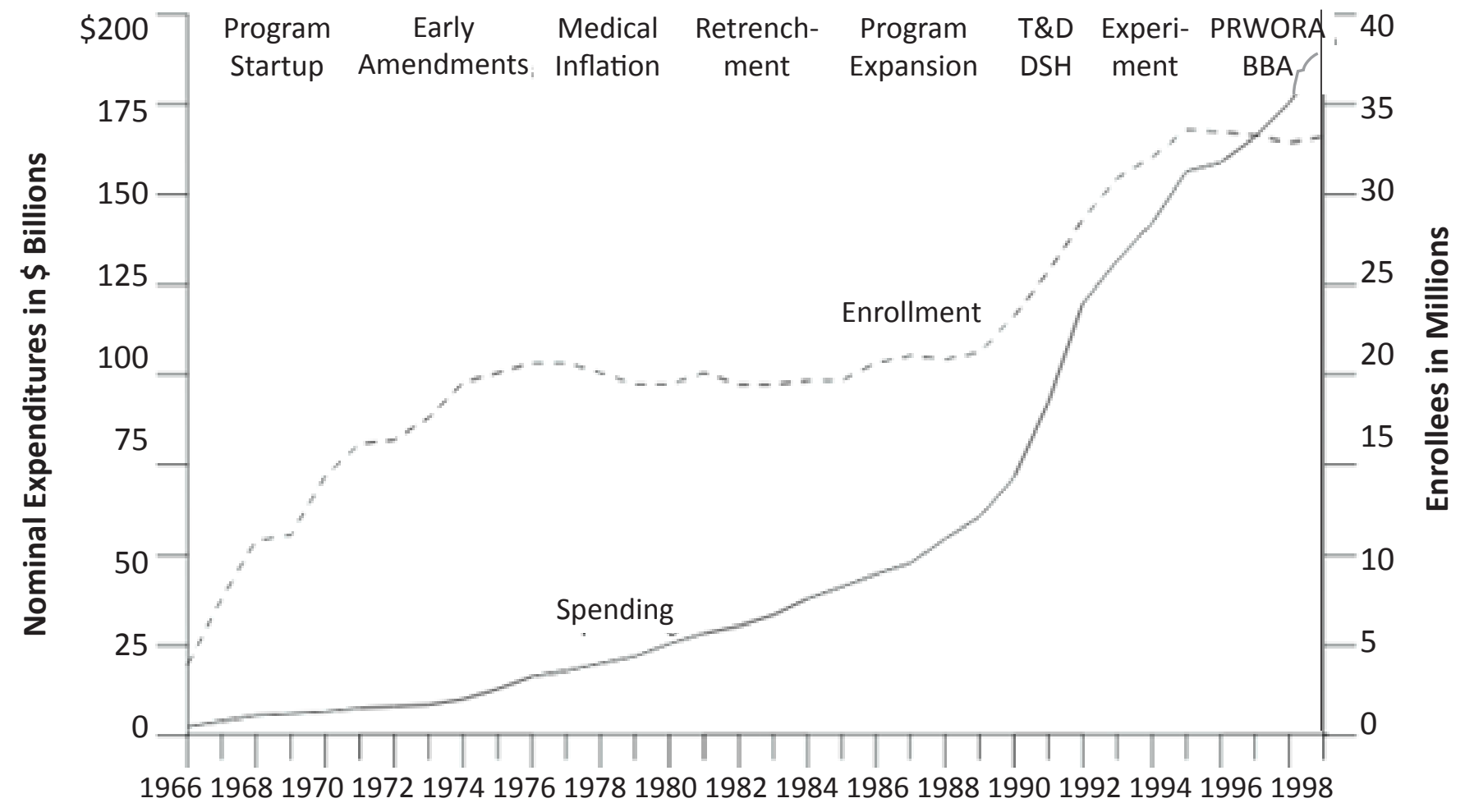

Federal Fiscal Year

\section{Figure 1 The growth in Medicaid. [CMS report on Medicaid ${ }^{2}$ ]}

Figure 1 shows the growth in Medicaid. The figure is taken from a CMS report on Medicaid ${ }^{2}$. The nonlinear trajectories of enrollment and spending were driven by public policy dividing the history of Medic-

Corresponding author: Gilbert Berdine MD Contact Information: Gilbert.Berdine@ttuhsc.edu DOI: 10.12746/swrccc 2013.0104.051 aid into eras. From 1966 - 1976 both enrollment and spending increased over time as the individual states ramped up their Medicaid programs. From 1976 1989 enrollments were flat with total spending increasing due to increases in average benefit. These benefit increases were affected by general price inflation.

There were two major factors for increasing enrollment from 1989 - 1995. Prior to 1988, Medicaid 
benefits had been linked to AFDC benefits. Starting in the late Reagan years, the link between Medicaid and AFDC was broken and replaced by a link to U.S. poverty lines. The second factor was a financing strategy known as Taxes and Donations which was linked to a class of provider known as Disproportionate Share Hospital (DSH).

Federal DSH payments were intended to assist hospitals that provided a large percentage of their care to unfunded or poorly funded patients. A State could increase its DSH payment to a hospital to any level, and then recoup the funds through taxes or donations from the providers. Unlike all other Medicaid payments, there were no limits to federal assistance via the DSH mechanism. By 1992, DSH payments grew to $15 \%$ of all Medicaid funding. The Medicaid Voluntary Contribution and Provider Specific Tax Amendments of 1991 closed this loophole. The Amendments made DSH payments less at- tractive to providers and capped the total amount of DSH payments to $12 \%$ of Medicaid funding. ${ }^{2}$

From 1995 - 1999 Medicaid enrollments reached another plateau while spending continued to rise. From 2000 - 2011 Medicaid enrollments increased from 34.5 million to 55.7 million and spending increased from $\$ 206.2$ billion to $\$ 427.4$ billion. There is much uncertainty about the effects of The Affordable Care Act (ACA) on the Medicaid program. ACA allows for expansion of Medicaid to "almost all individuals under age 65 in families with incomes below 138 percent of the Federal Poverty Level."1 The U.S. Supreme Court ruled that the States could not be explicitly forced to participate via legislative fiat nor could they be implicitly forced to participate by the threat of withholding other Medicaid funding. Some States have declared they will not participate in the expansion of Medicaid making projections uncertain.

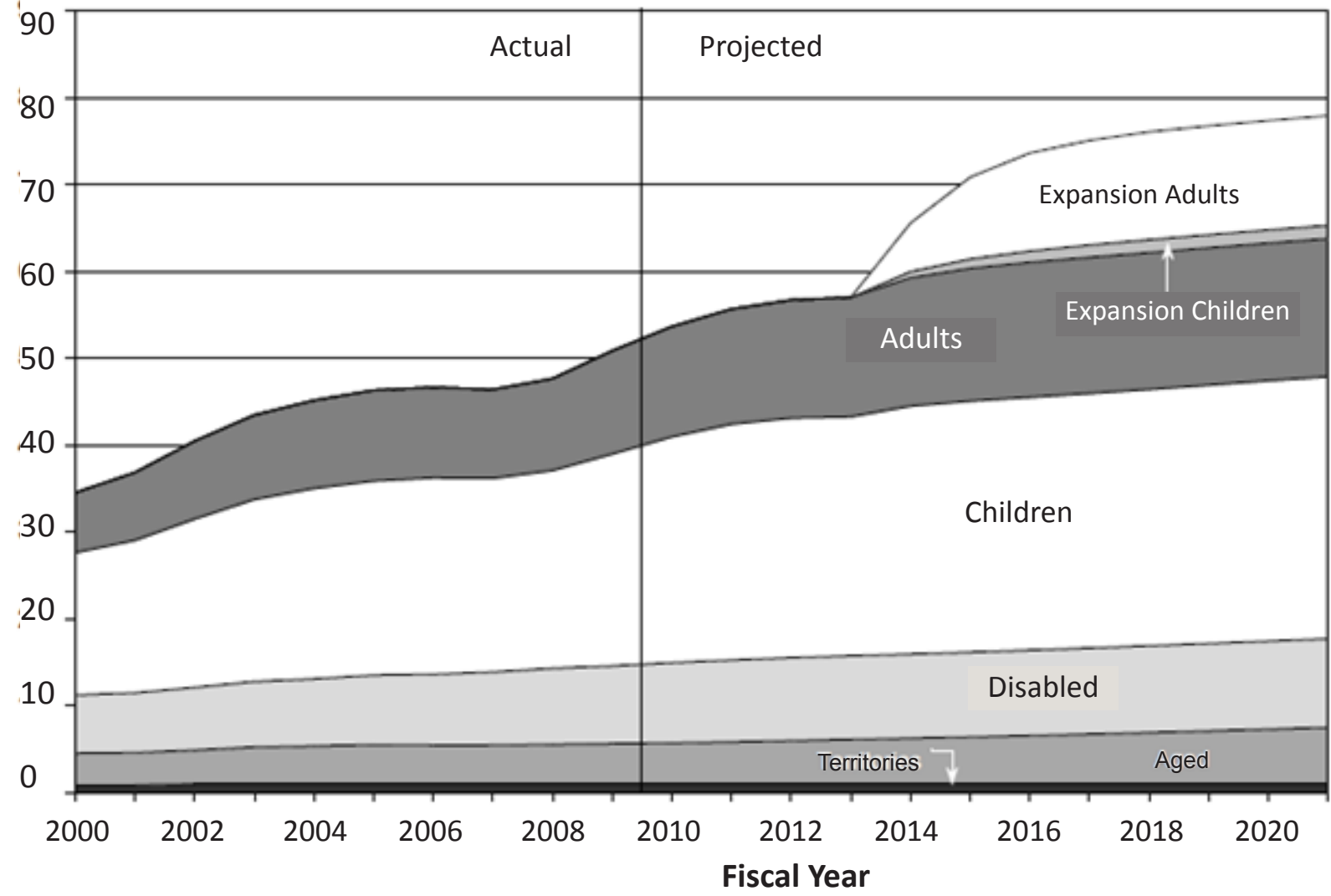

Figure 2 is taken from the Medicaid Actuarial Report of 2012. The y-scale is millions of Medicaid enrollees. Projections for the effects of ACA on enrollment are indicated. 
The U.S. government sets minimum standards for Medicaid eligibility, but each State may establish its own standards to include more people than the federal minimum. Texas Medicaid was established in 1967. Texas Medicaid spent $\$ 29.4$ billion during federal fiscal year 2011. The U.S. government paid $66.46 \%$ of these expenses and the State of Texas paid the remaining 33.54\%. During December, 20113.7 million Texas residents (14\%) received benefits from Texas Medicaid. Medicaid expenses were $26 \%$ of the Texas 2011 budget.

\section{Texas Medicaid Beneficiaries and Expenditure SFY 2011}

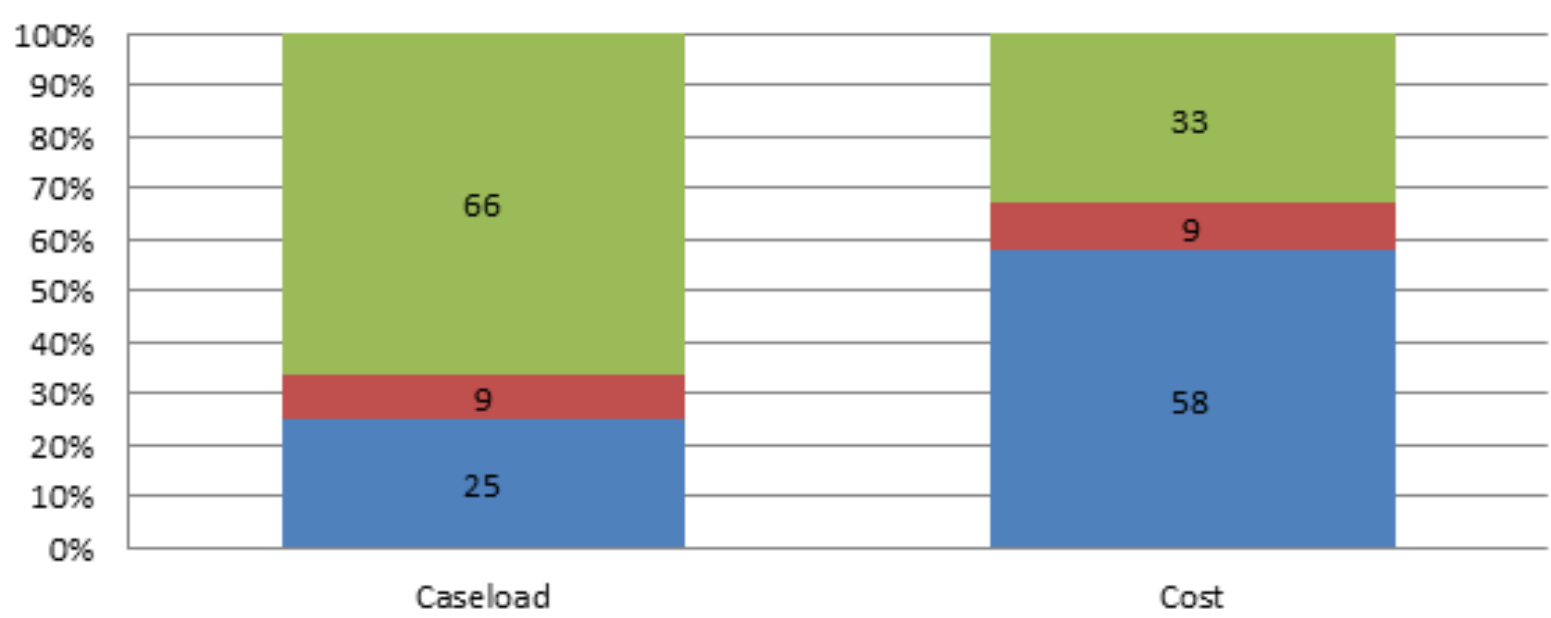

Aged/Disability Related $\square$ Non-Disability-Related-Adults $\square$ Non-Disability-Related Children

Figure 3 Texas Medicaid 2013 Report

Texas Medicaid Total Expenditures (Billions)

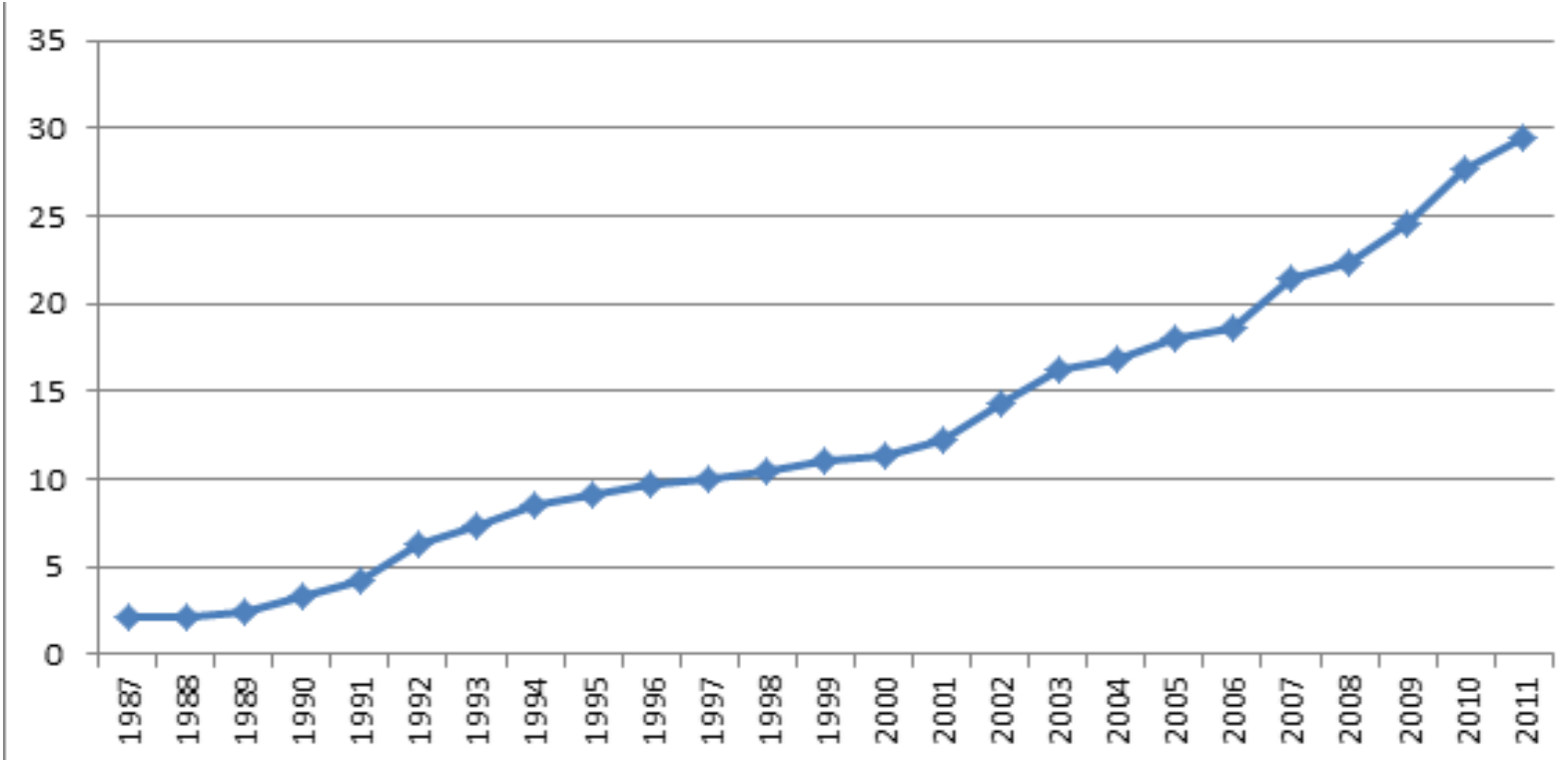

Figure 4 derived from data obtained from the Texas Medicaid 2013 Report ${ }^{3}$ 
Figure 3 is taken from the Texas Medicaid 2013 Report $^{3}$. It shows that expenses per beneficiary are skewed towards disability patients.

Figure 4 is derived from data obtained from the Texas Medicaid 2013 Report $^{3}$. Expenditures are growing faster than beneficiaries. Enrollment has grown from 2.61 million in 2001 to 4.57 million in 2011. Expenses per beneficiary are also rising from $\$ 4,711.49$ in 2001 to $\$ 6,440.26$ in 2011. Expenditures are rising faster than GDP and the Texas State budget, so Medicaid outlays are becoming an increasing percentage of the State budget.

The future trends of Texas Medicaid depend greatly on whether Texas participates in the ACA expansion of Medicaid or not.

Texas applied for a Section 1115 Waiver of federal Medicaid requirements ${ }^{4}$. This program (Texas Health Care Transformation and Quality Improvement Program) was approved by CMS on December 12, 2012. The waiver expands existing capitated managed care Medicaid programs (STAR and STAR + PLUS) to cover the entire state. The waiver also changes the statewide Upper Payment Limit fee-forservice spending cap with two new funding pools: an uncompensated care pool and a Delivery System Reform Incentive Payment (DSRIP) program for hospitals. The DSRIP program is part of a new "pay for performance" approach to health care funding.

A DSRIP program establishes quality assurance goals. Providers, both individual and institutional, are scored on how well they meet the goals. Providers with high scores may receive bonus payments and providers with low scores may receive penalties to reimbursement. Advocates of "pay for performance" believe the financial incentives will induce providers to improve the quality of care. Skeptics point out that performance scores can be influenced by patient selection; providers who skim the cream of the patient pool may achieve better scores without any change in practice behavior. These programs are currently in the monitoring phase with providers receiving score reports. The financial carrot/stick has yet to be ap- plied. The Texas Section 1115 Waiver is an example of an approved program in which hospitals are eligible for funds if they establish and implement "pay for performance" according to schedule.

Author Affiliation: Dr. Berdine is a pulmonary physician in the Department of Internal Medicine, TTUHSC.

Received: 8/16/2013

Accepted: 8/30/2013

Reviewers: Mark Funderburk, MBA, RHIA, FACHE, Kenneth Nugent MD

Published electronically: 10/1/2013

Conflict of Interest Disclosures: None

\section{References}

1. 2012 Medicaid Actuarial Report

2. https://www.cms.gov/Research-Statistics-Data-and-Systems/Research/HealthCareFinancingReview/downloads/ 00fallpg105.pdf

3. http://www.hhsc.state.tx.us/medicaid/reports/PB9/PinkBook.pdf

4. http://www.hhsc.state.tx.us/Wavier-1115-Proposal.pdf 